\title{
Exploring potential intervention strategies to reduce unsafe youth migration in Ethiopia: A mixed methods study
}

\author{
Kassahun Habtamu ( $\sim$ kasshabmek@gmail.com ) \\ Addis Ababa University https://orcid.org/0000-0001-8619-9388 \\ Abebaw Minaye \\ Addis Ababa University
}

Fantahun Admas

Addis Ababa University

Mesay Gebremariam

Addis Ababa University

Abera Tibebu

Addis Ababa University

Yohannese Adigeh

Addis Ababa University

Seleshi Zeleke

Addis Ababa University

\section{Research}

Keywords: Unsafe youth migration, illegal migration, intervention strategies, migration outcomes, mixed methods study, Ethiopia

Posted Date: January 10th, 2020

DOI: https://doi.org/10.21203/rs.2.20603/v1

License: (c) (1) This work is licensed under a Creative Commons Attribution 4.0 International License. Read Full License

Version of Record: A version of this preprint was published at Journal of International Migration and Integration on February 15th, 2021. See the published version at https://doi.org/10.1007/s12134-02100803-7. 


\section{Abstract}

Background Several studies investigated risk and protective factors for unsafe youth migration. However, evidence on what interventions help to reduce unsafe youth migration is lacking. This study aimed primarily to identify interventions that may help to reduce unsafe youth migration from the perspectives of key stakeholders.

Methods A mixed methods study was conducted in eight migration hotspot areas in Ethiopia. For the qualitative study, in-depth interviews and focus group discussions (FGD) were used to collect data. FGDs were conducted with students, teachers and parents separately. A school principal, heads of relevant offices of the local government, a community representative and a religious leader were interviewed. Thematic analysis was used to identify the prominent issues. Quantitative data were collected from students $(n=800)$, teachers $(n=240)$ and parents $(n=160)$ who were selected using multistage sampling. We developed a structured questionnaire to collect data. Descriptive statistics, t-test and one-way analysis of variance (ANOVA) were used to analyze the data.

Results We identified potential interventions to reduce unsafe youth migration and grouped them into five domains: awareness and attitudinal/behavioral changes, job opportunities and training, governmental and parental roles, improving the education system, and law enforcement and migration management. The need for cooperation among stakeholders was cross-cutting. More than $80 \%$ of the survey respondents agreed or strongly agreed in that the interventions would potentially be relevant and effective. We found significant mean difference in the degree of endorsement due to age and level of education in two of the domains of interventions (i.e. enhancing access to resources and jobs and law enforcement and managing migration). Older and more educated respondents were highly likely to endorse intervention strategies more than younger and less educated respondents. Significant mean difference was observed in one of the domains (i.e. law enforcement and managing migration) due to respondent type. Teachers and parents were more likely than students to endorse the intervention.

Conclusion We identified contextually relevant intervention strategies that would potentially be effective to reduce unsafe youth migration in Ethiopia. We suggest that there is to prioritize and empirically test the effectiveness of these intervention strategies.

\section{Background}

Migration is a global phenomenon which has been part of the human history at all times and across countries [1]. Migration is a highly heterogeneous process, both in terms of quality and quantity [2]; it may involve one individual, a family or a group of families [1,3]. Although accurate figures on the prevalence of international migration are impossible to determine, the International Labor Organization (ILO) estimated that there are 244 million cross-border migrants in 2015, of which 150 million are labor migrants [4]. Around $12 \%$ of international migrants (roughly one out of eight) are youth (defined as those between 15 and 24 years of age) [5]. The number of international migrants (persons living outside their 
country of birth) has continued to grow worldwide rapidly over the past 15 years [6] reaching 244 million in 2015, up from 173 million in 2000 [7]. The number of migrants through illegal means is also on the increase and it will continue to hike in the future owing to the existing humanitarian situations in various parts of the world [8]. Ethiopia is one of the big sources of migrant flow particularly to the Middle East and South Africa [9]. The number of international Ethiopian migrants is estimated to be 1.5 million, and each year close to 120,000 Ethiopians migrate [8].

Studies show that poverty, overpopulation, unemployment, environmental degradation, war, natural and man-made disasters are major push factors for migration worldwide [10,11]. Particularly in Africa, lack of livelihood opportunities, negative attitudes attached with low paying informal jobs and poor work ethics are considered as major causes for migration $[9,12]$. However, lack of employment opportunities is consistently cited as the major one. It is generally well-documented that poverty, system failure, actions of organized criminal groups like traffickers, smugglers and brokers, family and peer pressure act as causes for the high prevalence of legal and illegal migration in Africa in general and in Ethiopia in particular [13]. Positive attitudes towards migration, risk perception and readiness to migrate are also important emerging reasons for unsafe youth migration [9]. Several studies from Ethiopia also found that youth unemployment/underemployment, conflict, poverty, income inequality, household indebtedness, population pressure, lack of good governance, landlessness, low agricultural productivity and agroclimatic disasters, low wages and insecure informal economic activities are important causes for the youth to leave their homes $[7,8,14]$. There are also several pull factors for migration. These include attractive working conditions and demand for cheap labor in destinations, the growth of the service industry and aging population in developed countries and booming oil economy in the Middle East [15].

International migration has both positive and negative consequences for the sending and receiving countries. Migration contributes for the development of countries of origin (sending countries) in terms of remittance, job opportunities and technology and skill transfer; whereas for destination countries, migration contributes in terms of labor supply, cultural exchange and skill transfer [8]. It brings about an increased level of urbanization, and a means of achieving economic efficiency and equity [7]. Migration is regarded as a good cause for social diversity as well as a necessary condition for the creation and strengthening of a sense of nationhood [5]. Migration, through creation of diverse workforce with a wide range of skills and experiences, is more likely to benefit receiving countries [9].

The problem comes when migration, particularly cross-border migration, is carried out illegally, which brings about adverse impacts on the migrants, sending households, source countries and the host communities in the destination countries $[7,16]$. The most critical consequences of illegal cross-border migration include security and economic aspects [4]. Organized crime in destination countries is also another important consequence of illegal migration $[17,18]$. Illegal migration is a cause and consequence of inequality and unequal development as the immigrants sometimes are unable to access, at least temporarily, the existing services such as housing in their destinations [5]. 
Unsafe and stressful migration affects migrants, their families and source and receiving countries in general. Unsafe migration is found to have impact on migrants physical, psychological, social and economic wellbeing [8], which include drowning, enslavement, trafficking, sexual exploitation, labor exploitation, and organ harvesting $[19,20]$. For instance, a qualitative study of female Ethiopian migrants to the Middle East found experiences of exploitation, enforced cultural isolation, undermining of cultural identity and thwarted expectations [21]. Another qualitative study on migrant returnees from the Middle East also indicated that conditions for Ethiopian workers abroad are marked by frequent exploitation, neglect, and physical and sexual abuse [22]. A recent survey of migrant returnees from the Middle East and South Africa found a high burden of mental health problems resulting from adverse migration experiences, with $27.6 \%$ respondents reporting symptoms of common mental disorders [23]. Enhancing the positive and reducing the negative consequences of migration call for effective migration management which is informed by empirical evidence.

There is ample evidence on what determines (risk and protective factors) unsafe migration [22]. However, research on what interventions may help to reduce unsafe youth migration is lacking, particularly from Sub-Saharan Africa. A systematic review of available studies, mostly from South East Asia and South America, identified most commonly used interventions to reduce negative migration outcomes [24]. These include awareness campaigns, informational education material distribution, capacity building with local partner organizations and government agencies, employment placement, skill-building, migrant resource centres, hotlines, home visits to migrant families, legal assistance, network building for partners and beneficiaries, peer educator training, pre-departure orientation seminars, and psychosocial support. Nevertheless, the theoretical and empirical basis of these interventions is not clear. More research is needed to identify specific contextually relevant strategies that may help to reduce unsafe youth migration rather than investing to scale-up existing ones.

This study was conducted as part of a larger thematic research project that aimed to pilot implementation and effectiveness of contextually identified interventions to reduce unsafe youth migration in Ethiopia. The overall aim of the study is, therefore, to identify specific interventions that may help to reduce unsafe youth migration from the perspectives of key stakeholders. The study also aimed at determining the extent to which survey respondents endorse the usefulness of the interventions identified and the extent to which the endorsement differ in terms of basic background characteristics, including sex, age, religion, number of years of education completed, occupation or respondent type and study site.

\section{Methods}

\section{Study design}

A mixed methods, specifically exploratory sequential, study was conducted to identify interventions (which may help to reduce negative migration outcomes) and determine their contextual relevance from the point of view of teachers, parents and students. 
This study was carried out in eight migration hotspot areas (Dessie, Jimma, Assela, Atsbi Wonberta, Butajira, Hossana, Shoa Robit and Kemissie) from four regional states in Ethiopia. Dessie, Shoa Robit and Kemissie are from Amhara Regional State; Jimma and Assela from Oromia Regional Sate; Butajira and Hossana from Southern Nations, Nationalities and Peoples' Regional Sate; and Atsbi Wonberta from Tigrai Regional State. These study sites were selected based on evidence from previous studies which confirmed that migration is highly prevalent in these hotspot areas $[8,25]$.

\section{The qualitative study}

\section{Participants}

In order to select the participants for the qualitative study, multistage sampling method was used. First, eight migration hotspot areas were selected purposively as research sites. In the second stage, one school (which has both junior and general secondary grades) was selected in each study site for accessing students, teachers and parents as data sources. In the third stage, 16 students from grades seven to ten, eight teachers teaching from grades seven to ten, the school principal and five parents who were working as members of the Parent-Teacher-Student Association (PTSA) of the schools were purposively selected and involved in the study. Those students and teachers who had knowledge and experience on the problems of migration and were able to provide consent participated in the study. Heads of relevant offices of the local government (police, justice, women and children affairs, youth affairs, labor and social affairs, education, medium and small manufacturing enterprise) in each study site were invited to participate in the interviews. In addition, a community representative and a religious leader (either from Christian or Muslim) were interviewed from each study site.

\section{Data collection methods and procedures}

In-depth interviews and focus group discussions (FGD) were used to collect data. Fifty six in-depth interviews (seven in each study site) were carried out with heads of offices of the local government and the school principal. We were not able to use FGD for these participants as it was difficult to bring them together from different offices. The experiences and power hierarchies of these participants are also different, and running a comfortable discussion was difficult. So, FGDs were rather conducted with teachers, students and parents. Accordingly, thirty two FGD (four in each study site) were conducted. Eight FGDs were conducted with teachers (one in each site). Sixteen FGDs were held with students (one FGD with students from grades 7 and 8 in each site and another with students from grades 9 and 10). Then eight FGDs were run with parents (one in each site). FGD was used with all the three groups (students, teachers and parents) to elicit more information through their interaction and to encourage sharing of their experiences. In each FGD, eight to ten respondents were involved except in one of the FGDs with parents, where only five participants were involved. 
Almost all of the in-depth interviews and FGDs were conducted in Amharic, the official language of Ethiopia. Researchers of the larger thematic research project, where this study is nested in, conducted all FGDs and in-depth interviews. All of these researchers have training and several years of experience in qualitative data collection. While these researchers were moderating FGDs, their respective note takers or field assistants summarized the discussions and noted the non-verbal communication. In-depth interviews with heads of local government offices and the school principal were conducted in their respective offices; whereas the interviews with community representatives and religious leaders were carried out in a comfortable place in each town, , including their home, cafeteria, hotels, and churches/mosques. The FGDs with students, teachers and parents were carried out in a free classroom in the selected school. Privacy was assured at all times.

All interviews and FGDs were tape-recorded, with the consent of the participants. Generally, in-depth interviews lasted between 40 to 80 minutes, whereas FGDs lasted between 60 minutes to 120 minutes. As part of the main study, participants were asked four relevant issues (unsafe youth migration, quality of education, gender and the nexus among these three). The migration component of the questions dealt with the conceptualization, trend in terms of magnitude, causes, consequences of unsafe migration in the study site and the intervention strategies that may help to reduce unsafe migration. Planned probes, which included questions, related to causes, consequences and interventions for unsafe migration were identified from the existing local and international literature [7, 9, 22, 23, 26, 27]. The topic guide was developed iteratively as data collection and preliminary analysis continued.

\section{Data analysis}

The interviews and FGDs were transcribed verbatim by experienced transcribers. Track changes were used to facilitate data management. Data analysis was undertaken in parallel with data collection, with frequent discussion of the emerging themes among members of the research project. Thematic analysis [28] was used to identify the prominent issues from the data. Themes and categories were compared between the different respondent groups. The first author coded two transcripts, and coding schemes were discussed with the second author. The first author coded the remaining transcripts applying the already identified codes and drawing upon additional codes where the data required, frequently discussing with the second author. Higher order codes were derived from the primary codes with thorough discussion between the first and second authors. Similarly, overarching themes were developed from the higher order codes. Illustrative quotes were selected for each theme.

\section{The quantitative study}

\section{Participants}

Quantitative data were collected from students, teachers and parents. The purpose of the quantitative study was to determine the extent to which intervention strategies to reduce unsafe migration, identified through the qualitative study, are endorsed and considered relevant by a large sample of respondents. 
The study sites and the criteria used to select them are the same as the qualitative study (as described above).

We used multistage sampling in order to select the participants of the study. In the first stage, eight migration hotspot areas (Dessie, Jimma, Assela, Atsbi Wonberta, Butajira, Hossana, Shoa Robit and Kemissie) were purposively selected to be research sites. In the second stage, one school (with grades seven to twelve) and one technical and vocational education and training (TVET) college were again purposively selected in each site. Then, one section from each grade level (grades seven to twelve) and a section from the TVET College were randomly selected. One hundred students (10 from grades seven, eight, eleven, twelve and the TVET college and 25 students from grade nine and ten) in the selected sections were randomly selected and invited to take part in the study. More students were selected from grade nine and ten because students at this level are highly vulnerable to migration. Those below grade nine are too young for migration and those at preparatory level have better hope of joining University and thus they are less likely to migrate. Thirty teachers teaching in grades seven through twelve were randomly selected and invited to participate. In addition, 20 parents who had at least one child in the school were recruited through the school principals and members of the PTSA.

Overall, 150 respondents (100 students, 30 teachers and 20 parents) from each site, and 1200 from all the study sites (800 students, 240 teachers and 160 parents) were involved as participants for the survey in this study. Missing data were less than $5 \%$ in all of the items in the questionnaire.

\section{Measures}

We developed a structured self-administered questionnaire for the larger thematic research project to assess the situation of unsafe migration, quality of education and gender in the study sites. We use findings of the qualitative study and extensive review of the existing literature to develop the questionnaire. Specifically, the questionnaire was designed to gather data related to trends, causes, consequences of unsafe migration and potential intervention strategies to reduce unsafe migration; input, process and output indicators of quality of education; nexus between education and migration and nexus between gender and migration. The draft questionnaire was reviewed by experts who have training and experience on developing research instruments. We pilot-tested the questionnaire with small sample in one of the study sites and improvements were made incorporating feedback from the experts and findings of the pilot study. Internal consistency reliability was determined and some vague or unclear items were rewritten. A few unnecessary items were removed and other items were added as per the suggestion of the experts. The questionnaire took an hour, on average, to complete.

For the study reported in this paper, data collected using section IV of the questionnaire (strategies to mitigate youth unsafe migration) was used. Similar to the other sections of the questionnaire, this section of the questionnaire was developed being informed by findings of the qualitative study and extensive review of the existing literature. The questionnaire presented fifteen potential intervention strategies and asked participants to rate the extent to which they agree or disagree about the contextual relevance, feasibility and effectiveness of those intervention strategies in order to reduce unsafe youth migration. 
The fifteen items measuring potential intervention strategies were grouped into three meaningful domains through expert discussion involving migration and measurement professionals: working on values and behavior, enhancing access to resources and jobs and law enforcement and migration management. Exploratory factor analysis confirmed the expert decision and each item fairly loaded to the respective domain with cross-loading of few of the items. Internal consistency reliability of items of the overall scale was 0.91 ; whereas internal consistency reliability of items of the sub-scales working on values and behavior, enhancing access to resources and jobs and law enforcement and migration management were found to be $0.74,0.80$ and 0.83 , respectively. Aggregate scores were computed for each sub-scale to facilitate further statistical analysis.

A structured background characteristics questionnaire was developed and used to collect data on the sex, age, education, religion and occupation of the respondents. Experienced field workers, who have at least diploma level education, were employed to collect the data. Researchers from the larger thematic research project supervised the field workers (one supervisor was assigned for each study site). Training was provided for a day to the field workers focusing on the content of the questionnaire, ethical issues to be observed and ways of approaching respondents.

\section{Data analysis}

Data were checked for completeness and consistency by the field supervisors during data collection. Data entry was carried out using Statistical Packages for the Social Sciences (SPSS version 22). Data were entered by a trained and experienced data entry clerk. The first author cleaned the data after data entry and before data analysis began using frequencies and logic checks. Descriptive statistics (frequency and percentage) were used to summarize the background characteristics of the participants. Descriptive statistics were also used to determine the extent to which respondents endorsed and considered the intervention strategies as relevant to reduce unsafe youth migration. One-way analysis of variance (ANOVA) and t-test were used to determine the extent to which endorsement of the potential intervention strategies differ in terms of sex, education, religion and respondent type (teachers, students and parents) as appropriate. Statistical tests were set at $a=0.05$ for significance.

\section{Ethical considerations}

A technical committee established by the Office of the Vice President for Research and Technology Transfer (VPRTT) at Addis Ababa University reviewed and approved the study protocol for the larger thematic study. To that end, we secured a support letter from the VPRTT to collect data from the study sites. Permission to collect data was obtained from the concerned offices in all the study sites by presenting a cooperation letter written from Addis Ababa University. Concerned offices are local government offices mandated to work on migration, education, gender, security and related issues, which include Labor and Social Affairs Office, Justice Office, Women and Children Affairs Office, Youth Affairs Office, Education Office, Medium Manufacturing Enterprise and the Police. Participation was voluntary and verbal informed consent was obtained from all the participants after the nature of the study was fully explained to them. Verbal informed consent was preferred to written informed consent just to put 
respondents at ease since informants may not be comfortable to put their signature on paper in the Ethiopian socio-cultural context. Respondents were explicitly informed that they could withdraw at any time from the study and cease to respond to any question they felt uncomfortable. Information obtained from all the participants was anonymized and confidentiality was assured throughout the data collection process.

\section{Results}

\section{i) Findings from the qualitative study}

In responding to the question "what shall be done to reduce unsafe youth migration", participants suggested a long list of intervention strategies that would help to deal with unsafe youth migration and the consequent undesirable migration outcomes in Ethiopia. These specific intervention strategies identified are grouped into five broad categories: creating awareness and bringing attitudinal/behavioral changes, creating job opportunities and providing training, fulfilling governmental and parental roles, improving the education system, and law enforcement and managing migration. In describing the different intervention strategies, which would help to reduce unsafe youth migration, participants from the three groups in different study sites focused on the need for cooperation among stakeholders. It was emphasized that there should be cooperation among elders, teachers, parents; religious institutions, schools, the community, the government, non-governmental organizations, law makers, the executive body, and different local government offices mandated to manage migration.

\section{Awareness and attitudinal and behavioral changes}

All groups of participants across study sites emphasized the importance of creating awareness regarding the negative consequences and harms of unsafe migration and subsequently changing attitudes and behavior of the youth, their parents and the community at large. In connection with awareness creation activities, the participants suggested to educate the youth, their parents and the community through several formal and informal structures. Interview and FGD participants particularly advised to use migrant returnees as witnesses and support them to share their experiences. Some participants suggested teaching with the support of video films (showing the negative experiences of those who migrated illegally). During focus group discussions, making religious institutions to educate their followers and using local and informal social structures such as "Idir" (informal insurance groups) to educate parents and the community were reiterated. Participants mentioned the importance of establishing formal and regular discussion forums at the community level to make the awareness creation activities sustainable. Regarding the need for awareness creation activities, a FGD participant noted the following. 
It is critical to give education [about illegal migration] to parents and the community in schools through clubs and make students aware of the problems. Schools do have potential to create awareness among students and the community in general. (FGD with Parent-Teacher Association Members, Atsbi Wonberta)

Participants from all the study sites unanimously underlined the need to bring about attitudinal and behavioral changes, particularly among the youth and their parents. It would be immensely important for the youth to understand that it is possible to work and change their life here within the country. In addition, it would bring difference if the youth understand the harms, risks and negative consequences of migration particularly unsafe and illegal migration. A prosecutor from one of the sites reflected his view as follows:

We have to exert all our efforts at the grass root level to create awareness so that the youth would change their attitude to work in their home country. I know there are laws, policy and different banning directives on migration in Ethiopia; and we are also working some tasks as justice officers on migration; but still there is an increasing number of migrants in our locality. This is not because there is no law or punishment of illegal migrants, but unless we work on the attitude and change the mind of youth, we cannot solve the problem. (In-depth interview with a prosecutor from District Justice Office, Jimma)

Some participants pointed out that the concerned body should work hard and educate the youth in order to improve work ethics and work culture among the youth, make the youth love their country and have sense of citizenship. Similarly, awareness creation activities using the right media, at the right setting should be done to change the youth so that they would not undermine locally available jobs, work whatever job they get and engage in available jobs here within the country. Continuous and sustained awareness creation activities have to be done to make the parents understand the problems of unsafe migration and change their attitudes since much of the pressure for the youth to migrate come from the parents and other family members.

\section{Creating opportunities for job and training}

Participants from every study site emphasized that the major reason for the youth to choose to leave their country is lack of job opportunities which subsequently lead to poverty. Accordingly, interview and FGD participants suggested that creating job opportunities, particularly expansion of manufacturing industries, would be a sustainable solution to deal with unsafe youth migration. One of the participants in the FGD held with high school students at Kemissie described this as: “... to reduce unsafe youth migration the government and concerned non-governmental organizations have to organize the youth and create job opportunities for them." In addition, it was highly recommended for the government to organize the youth fairly and without discrimination, arrange loans with low interest rate and make the loan process less bureaucratic and simple. Participants also indicated that 
arranging employment opportunities for new university graduates would be important to address the increasing low value being given to education by students which in turn can help to reduce school dropout and the lower motivation and interest of students towards education. All these interventions were believed to reduce youth unemployment and joblessness, which are the root causes of unsafe youth migration in Ethiopia.

Related to creating job opportunities and expanding manufacturing industries, participants underlined the necessity of providing vocational and life skills training for the youth. The concerned government offices were advised to provide focused, hands on and practical training for the youth in collaboration with other stakeholders, such as schools and nongovernmental organizations. This would help the youth to increase their motivation for work and entrepreneurial skills. Some participants from a few of the study sites suggested that the government should plan facilitating skilled migration by providing potential migrants with marketable skills. This includes offering intensive and compulsory premigration training so that migrants would be internationally competitive and successful. One of the FGD participants with teachers commented as follows.

There must be training-based legal migration in the country. If potential youth migrants are well trained, they will be useful to the country. To make migrants internationally competent, they should be provided vocational skills training. There is also need to provide life skills training for the youth properly and need to educate them about how they would realize their dream. (FGD with teachers, Shoa Robit)

\section{Governmental and parental roles}

Participants identified several roles that the government should play and responsibilities that it should discharge as important intervention strategies to deal with unsafe youth migration in Ethiopia. Interview and FGD participants strongly advised the government to effectively and efficiently implement migration related policies and plans and optimize the performance of the executive body at different levels to put these provisions into effect. Moreover, participants suggested the government to work on and bring about change on different aspects of good governance, including providing equal opportunity, avoiding discrimination, ensuring gender equality and most importantly reducing corruption. The government also needed to do its best in terms of creating jobs and eventually reducing poverty, both at the household level and at the population level. Some participants also advised the government, at different levels, to encourage the youth to use the legal way for migration by way of making the process easier and less expensive; whereas to discourage illegal migration through follow-up and strict monitoring. A parent from Dessie who participated in the FGD reflected his/her view as follows:

The major thing is the role of the government. The government has to close borders and make serious patrolling. It has to support migration only through legal means. There should be serious control of the illegal brokers. The government has to also create job opportunities, particularly for women. The government has created jobs 
and made things suitable for rich investors, but, it has to prioritize and make jobs available for the poor and for those who have no jobs. (FGD with parents, Dessie)

In addition, most of the participants mentioned roles of the government such as establishing a separate mandated institution that would manage migration, increasing salary for civil servants (particularly of primary school teachers and health extension workers), creating political stability in the country and providing land and other resources primarily to the youth rather than to investors. It would also be useful if the government build the capacity of district officers who are working in areas related to job creation, providing loan, organizing the youth and managing migration. Some participants emphasized that alongside creating jobs for those who have no job, the government should create a conducive or decent work environment for those who are already employed. A school principal from Butajira described this as ....."the government needs to seriously consider the salary and work condition of government employees; large numbers of teachers and health extension workers leave their job and go abroad since their salary is not enough for fulfilling their basic needs."

Participants underlined the role of the parents in reducing unsafe youth migration. First and foremost, parents needed to advise and educate their children about the harms of unsafe migration, the value of education and the importance of developing work culture. Parents needed to support and give continuous encouragement in the education and work life of their children. The other role that parents needed to play in terms of reducing unsafe youth migration was follow-up and monitoring of their children, particularly in relation to their education. Participants said that parents should control and monitor their children until they finish their education. Specifically, some participants advised parents to send their children to school and see their sons and daughters as equal and provide them equal opportunities. Regarding the role parents might play in reducing unsafe migration, education expert from Butajira district described it as:

To solve this problem [unsafe youth migration], it requires everyone to exert its effort. Parents need to be concerned about the security of their children and they need to send their children to school. Parents may provide small seed money for their children to start business. If they invest on the education of children, there would be a lot of change. So, parents are expected to advise their children well. Parents do give money for their children to finance migration and they are expected to stop this. (In-depth interview with District Education Office Head, Butajira)

Improving the education system

Interview and FGD participants, from the different study sites, stressed that one of the leading causes for youth migration is related to access and quality of the education system in the country. Hence, in order to deal with unsafe youth migration, participants advised to make university education and technical and vocational education and training (TVET) 
more accessible. The Ministry of Education (MoE) and other stakeholders should give attention and work on improving the quality of education.

When quality of education declines, students would not attend their education properly; drop out increases; and students' interest, motivation and performance decreases, all of which would contribute for the youth to consider leaving their country. Therefore, participants advised to make the school environment as comfortable as possible (example: classrooms and playing ground). To improve the quality of education participants suggested to increase teachers' interest and performance through increasing their salary and improving the respect and value being given to teachers and the teaching profession. A FGD participant with students commented as follows.

Moreover, participants suggested that, to bring about attitudinal and behavioral changes with regard to unsafe migration, it would be helpful to establish migration clubs in schools and strengthening existing ones. Participants also suggested incorporating migration in the school curriculum.

\section{Law enforcement and managing migration}

All groups of participants across the study sites stressed hunting illegal brokers and bringing them to court as a critical strategy to deal with unsafe youth migration. The Police needed to work hard to identify, control and punish illegal brokers. Coordinator of the District Small and Medium Manufacturing Industry Office from Atsbi Wonberta described this as: "The government has to control and take a serious action against illegal brokers and others who engage in the process of unsafe youth migration. There should also be a serious border patrolling."

It would also be important to make the public aware about consequences being involved in smuggling and trafficking by presenting punishments on illegal brokers, smugglers and traffickers through several means such as the media. Illegal brokers have a complex network and the police and all the other security apparatus should work in cooperation to break down their networks. Some participants also suggested for sustained and continuous patrolling and controlling around border areas as a means to find the brokers and break down their networks. Furthermore, it would be important to make the community aware about and expose illegal brokers. In relation to law enforcement and managing migration, participants emphasized that there should be strict enforcement of existing legal instruments (national, regional and international). Moreover, participants advised to make the community aware that unsafe or illegal migration is a crime.

ii) Findings from the quantitative study

Background characteristics of the respondents

A total of 1,187 respondents participated in the study (a response rate of 98.9\%). Of these, $55.4 \%$ were males and more than half (59.4\%) were below 20 years of age. Nearly $90 \%$ of 
the respondents had secondary or higher level education. In terms of religion, the majority were Orthodox Christian (61.3\%) followed by Muslim (26.7\%). Two third of the respondents were primary, secondary or TVET students, nearly one fourth were teachers and a little over ten percent were parents. There was almost equal distribution of the sample across the study sites. See Table 1.

Table 1: Background characteristics of the survey respondents $(\mathrm{N}=1,187)$

\begin{tabular}{|l|l|l|l|}
\hline Characteristics & Response categories & $\mathrm{N}$ & $\%$ \\
\hline Sex & Male & 656 & 55.4 \\
\hline & Female & 529 & 44.6 \\
\hline Age & $\leq 15$ & 238 & 20.3 \\
\hline & $16-19$ & 459 & 39.1 \\
\hline & $20-29$ & 200 & 17.1 \\
\hline & $30-39$ & 150 & 12.8 \\
\hline & $\geq 40$ & 126 & 10.7 \\
\hline Number of years of formal education completed & Less than eight years of education & 107 & 9.1 \\
\hline & $8-12$ years of education & 748 & 63.4 \\
\hline & $>12$ years of education & 325 & 27.5 \\
\hline Religion & Orthodox Christian & 715 & 61.3 \\
\hline & Muslim & 311 & 26.7 \\
\hline & Protestant & 138 & 11.8 \\
\hline & Catholic & 3 & 0.3 \\
\hline Respondent type & Student & 793 & 66.8 \\
\hline & Teacher & 262 & 22.1 \\
\hline & Parent & 132 & 11.1 \\
\hline Study site & Atsbi Wonberta & 149 & 12.6 \\
\hline & Dessie & 139 & 11.7 \\
\hline & Kemissie & 158 & 13.3 \\
\hline & Shoa Robit & 150 & 12.6 \\
\hline & Hossana & 138 & 11.6 \\
\hline & Butajira & 156 & 13.1 \\
\hline & Assela & 146 & 12.3 \\
\hline & Jimma & 151 & 12.7 \\
\hline & &
\end{tabular}

$N=$ number of participants

Distribution of the endorsement of intervention strategies identified with the qualitative study

We asked survey respondents to indicate their degree of agreement regarding the contextual relevance and effectiveness of the intervention strategies that participants of the qualitative study suggested as may be useful to reduce unsafe migration and improve the outcomes of migration. Accordingly, more than $80 \%$ of the respondents agree or strongly agree that all the interventions suggested would be contextually relevant and effective in 
terms of reducing unsafe youth migration as well as improving migration outcomes (Table 2 ). Only less than $10 \%$ of the respondents disagree or strongly disagree regarding the contextual relevance and effectiveness of these interventions. Specifically, changing the attitude/behavior of the youth, creating job opportunities, and law enforcement and managing migration effectively through punishing illegal brokers and having a national policy and a national agency that would give services on migration were considered important interventions to deal with unsafe youth migration.

However, around $62 \%$ of the respondents agree or strongly agree for one of the interventions (that is for promoting legal migration). For this intervention, around $27 \%$ of the respondents disagree or strongly disagree about its contextual relevance and effectiveness to reduce unsafe youth migration and improving migration outcomes.

Table 2: Respondents' degree of agreement for the contextual relevance and effectiveness of intervention strategies identified though the qualitative study 


\begin{tabular}{|c|c|c|c|c|c|}
\hline \multirow[t]{2}{*}{ itervention strategy } & \multicolumn{5}{|c|}{ Respondents' degree of agreement $(\mathrm{N}=1,187)$} \\
\hline & $\begin{array}{l}\text { Strongly } \\
\text { disagree }\end{array}$ & Disagree & Undecided & Agree & $\begin{array}{l}\text { Strongly } \\
\text { agree }\end{array}$ \\
\hline & $\mathrm{N}(\%)$ & $\mathrm{N}(\%)$ & $\mathrm{N}(\%)$ & $\mathrm{N}(\%)$ & $\mathrm{N}(\%)$ \\
\hline \multicolumn{6}{|l|}{ lorking on values and behavior } \\
\hline lorking for change in attitude/behavior of youth & $27(2.3)$ & $30(2.5)$ & $47(4.0)$ & $\begin{array}{l}320 \\
(27.1) \\
\end{array}$ & $756(64.1)$ \\
\hline Iorking on improvement of the quality of education & $39(3.3)$ & $42(3.6)$ & $59(5.0)$ & $\begin{array}{l}297 \\
(25.4) \\
\end{array}$ & $734(62.7)$ \\
\hline nhancing value for education & $45(3.9)$ & $47(4.0)$ & $89(7.6)$ & $\begin{array}{l}367 \\
(31.4) \\
\end{array}$ & $621(53.1)$ \\
\hline loral education on the value for work and citizenship & $27(2.3)$ & $38(3.2)$ & $62(5.3)$ & $\begin{array}{l}425 \\
(36.2) \\
\end{array}$ & $621(52.9)$ \\
\hline \multicolumn{6}{|l|}{ nhancing access to resources and jobs } \\
\hline $\begin{array}{l}\text { roviding training on entrepreneurial and life skill } \\
\text { evelopment }\end{array}$ & $25(2.1)$ & $27(2.3)$ & $67(5.7)$ & $\begin{array}{l}358 \\
(30.4) \\
\end{array}$ & $699(59.4)$ \\
\hline laking jobs decent & $25(2.1)$ & $42(3.6)$ & $67(5.7)$ & $\begin{array}{l}306 \\
(26.2) \\
\end{array}$ & $730(62.4)$ \\
\hline $\begin{array}{l}\text { asing the loan process (improved access and reduced } \\
\text { Iterest rate) }\end{array}$ & $46(3.9)$ & $58(5.0)$ & $105(9.0)$ & $\begin{array}{l}350 \\
(29.9) \\
\end{array}$ & $612(52.3)$ \\
\hline $\begin{array}{l}\text { laking access to resources (land, house, loan, education, } \\
\text { b, etc.) fair }\end{array}$ & $38(3.3)$ & $52(4.5)$ & $80(6.9)$ & $\begin{array}{l}296 \\
(25.4) \\
\end{array}$ & $701(60.1)$ \\
\hline \multicolumn{6}{|l|}{ aw enforcement and migration management } \\
\hline erious punishment on brokers & $54(4.6)$ & $76(6.5)$ & $105(9.0)$ & $\begin{array}{l}290 \\
(24.7) \\
\end{array}$ & $648(55.2)$ \\
\hline educing corruption & $43(3.7)$ & $59(5.0)$ & $66(5.6)$ & $\begin{array}{l}313 \\
(26.7) \\
\end{array}$ & $691(59.0)$ \\
\hline oordinating anti-trafficking and anti-smuggling efforts & $63(5.4)$ & $68(5.8)$ & $82(7.0)$ & $\begin{array}{l}346 \\
(29.5) \\
\end{array}$ & $614(52.3)$ \\
\hline aving full-fledged policy on migration & $40(3.4)$ & $60(5.2)$ & $82(7.0)$ & $\begin{array}{l}367 \\
(31.5) \\
\end{array}$ & $617(52.9)$ \\
\hline $\begin{array}{l}\text { aving a national agency that studies and gives service on } \\
\text { ligration }\end{array}$ & $44(3.8)$ & $59(5.0)$ & $101(8.6)$ & $\begin{array}{l}397 \\
(33.9) \\
\end{array}$ & $570(48.7)$ \\
\hline romoting legal migration & $149(12.7)$ & $\begin{array}{l}170 \\
(14.5) \\
\end{array}$ & $127(10.9)$ & $\begin{array}{l}323 \\
(27.6) \\
\end{array}$ & $402(34.3)$ \\
\hline erious border patrolling & $51(4.3)$ & 79 (6.7) & $118(10.1)$ & $\begin{array}{l}361 \\
(30.7)\end{array}$ & $565(48.1)$ \\
\hline
\end{tabular}

$N=$ number of participants

Difference in endorsement of intervention strategies in terms of background characteristics No statistically significant mean difference was observed in the degree of endorsement of respondents regarding the contextual relevance and effectiveness of all the three domains of intervention strategies (working on values and behavior, enhancing access to resources and jobs and law enforcement and migration management) in terms of sex and religion. In terms of age statistically significant mean differences were found with regard to the 
domains of enhancing access to resources and jobs $(\mathrm{F}=4.40, \mathrm{P}<0.05)$ and law enforcement and migration management $(\mathrm{F}=7.24, \mathrm{P}<0.05)$. Tukey Post hoc test showed that (data not available here) respondents with age less than 15 were found to have significantly lower mean value on the enhancing access to resources and jobs domain compared to all other age groups. With regard to law enforcement and migration management domain, respondents with age less than 15 and age 16-19 had significantly lower mean values compared to those with age 20-29 and 30-39. Overall, these findings showed that older respondents were more likely to endorse intervention strategies more than younger respondents.

We found statistically significant mean differences across levels of education of respondents in the enhancing access to resources and jobs domain $(F=6.06, p<0.05)$ and the law enforcement and migration management domain $(\mathrm{F}=7.70, \mathrm{P}<0.05)$. More specifically, in terms of mean value for enhancing access to resources and jobs, those who have less than eight years of education were significantly lower than both those with education 8-12 and $>12$ years. With regards to mean value for law enforcement and migration management, those who have greater than 12 years of education were found to have significantly higher mean value than both those with education less than eight years and 8-12 years. These indicated that respondents with higher level of education were more likely to endorse intervention strategies more than those with lower level of education. We found statistically significant mean difference across respondent type only in one of the three domains (the law enforcement and migration management domain) $(\mathrm{F}=7.36, \mathrm{P}<0.05)$. Tukey Post hoc tests showed that the mean level of endorsement of intervention strategies in the law enforcement and migration management domain of students was significantly less than both teachers and parents.

Mean values for level of endorsement of intervention strategies differed significantly across the study sites in all the three domains of interventions. In the values and behavior domain of interventions $(\mathrm{F}=11.08, \mathrm{P}<0.01)$, degree of endorsement in Dessie was greater than Astbi, Kemissie, Hossana, Jimma and Arsi, whereas Butajira was greater than Atsbi, Kemissie, and Jimma; Shoa Robit was greater than Kemissie and Jimma. In the access for resources and jobs domain $(\mathrm{F}=14.27, \mathrm{P}<0.01)$, Dessie was greater than Atsbi, Kemissie, Hossana and Jimma; Shoa Robit was greater than Atsbi, Kemissie and Jimma; Butajira was greater than Atsbi, Kemissie and Jimma; and Assela was greater than Atsbi and Kemissie. In the law enforcement and migration management domain $(\mathrm{F}=20.2, \mathrm{P}<0.01)$, Dessie was greater than Atsbi, Kemissie, Shoa Robit, Hossana, Arsi and Jimma; whereas Butajira was greater than Atsbi, Kemissie, Shoa Robit, Hossana, Arsi and Jimma. It seemed generally that the level of endorsement of intervention strategies in the three domains was higher in Dessie and Butajira compared to the other sites although it was high in all of the study sites. 
Table 3: Difference in the endorsement of intervention strategies in terms of background characteristics

Page 18/25 


\begin{tabular}{|c|c|c|c|c|c|c|c|c|c|c|}
\hline & & \multicolumn{3}{|c|}{$\begin{array}{l}\text { Working on values and } \\
\text { behavior }\end{array}$} & \multicolumn{3}{|c|}{$\begin{array}{l}\text { Enhancing access to } \\
\text { resources } \\
\text { and jobs }\end{array}$} & \multicolumn{3}{|c|}{$\begin{array}{l}\text { Law enforcement and migration } \\
\text { management }\end{array}$} \\
\hline & & $\begin{array}{l}\text { Mean } \\
(\mathrm{SD})\end{array}$ & $\mathrm{t} / \mathrm{F}$ & $\begin{array}{l}\mathrm{P} \text { - } \\
\text { value }\end{array}$ & $\begin{array}{l}\text { Mean } \\
(\mathrm{SD})\end{array}$ & $t / F$ & $\begin{array}{l}\mathrm{P} \text { - } \\
\text { value }\end{array}$ & Mean (SD) & $t / F$ & P-value \\
\hline & Male & $\begin{array}{l}17.5 \\
(2.5)\end{array}$ & -0.69 & 0.75 & $\begin{array}{l}17.5 \\
(3.1)\end{array}$ & 0.45 & 0.33 & $28.9(5.6)$ & 0.38 & 0.35 \\
\hline & Female & $\begin{array}{l}17.6 \\
(2.5) \\
\end{array}$ & & & $\begin{array}{l}17.4 \\
(2.9)\end{array}$ & & & $28.8(5.4)$ & & \\
\hline & $\leq 15$ & $\begin{array}{l}17.2 \\
(2.8) \\
\end{array}$ & 2.13 & 0.07 & $\begin{array}{l}16.8 \\
(3.2) \\
\end{array}$ & 4.40 & $<0.05$ & $27.6(5.5)$ & 7.24 & $<0.05$ \\
\hline & $16-19$ & $\begin{array}{l}17.5 \\
(2.6)\end{array}$ & & & $\begin{array}{l}17.5 \\
(2.8)\end{array}$ & & & $28.6(5.4)$ & & \\
\hline & $20-29$ & $\begin{array}{l}17.8 \\
(2.8) \\
\end{array}$ & & & $\begin{array}{l}17.9 \\
(2.9) \\
\end{array}$ & & & $30.0(5.4)$ & & \\
\hline & $30-39$ & $\begin{array}{l}17.9 \\
(2.8)\end{array}$ & & & $\begin{array}{l}17.7 \\
(3.2)\end{array}$ & & & $30.1(5.5)$ & & \\
\hline & $\geq 40$ & $\begin{array}{l}17.3 \\
(3.4) \\
\end{array}$ & & & $\begin{array}{l}17.7 \\
(3.2)\end{array}$ & & & $29.2(5.6)$ & & \\
\hline \multirow[t]{3}{*}{$\begin{array}{l}\text { ber of years of } \\
\text { ation }\end{array}$} & $\begin{array}{l}\text { Less than eight } \\
\text { years }\end{array}$ & $\begin{array}{l}17.1 \\
(2.4)\end{array}$ & 1.36 & 0.26 & $\begin{array}{l}16.6 \\
(2.8)\end{array}$ & 6.06 & $<0.05$ & $27.5(5.3)$ & 7.70 & $<0.05$ \\
\hline & $8-12$ years & $\begin{array}{l}17.6 \\
(2.7)\end{array}$ & & & $\begin{array}{l}17.5 \\
(2.9)\end{array}$ & & & $28.7(5.4)$ & & \\
\hline & $>12$ years & $\begin{array}{l}17.6 \\
(3.1) \\
\end{array}$ & & & $\begin{array}{l}17.8 \\
(3.2)\end{array}$ & & & $29.8(5.8)$ & & \\
\hline \multirow[t]{3}{*}{ ion } & Orthodox & $\begin{array}{l}17.5 \\
(2.8) \\
\end{array}$ & 0.04 & 0.97 & $\begin{array}{l}17.5 \\
(3.0)\end{array}$ & 0.20 & 0.82 & $28.8(5.4)$ & 0.86 & 0.42 \\
\hline & Protestant & $\begin{array}{l}17.6 \\
(3.5)\end{array}$ & & & $\begin{array}{l}17.5 \\
(3.6)\end{array}$ & & & 28.7 (6.7) & & \\
\hline & Muslim & $\begin{array}{l}17.5 \\
(2.5) \\
\end{array}$ & & & $\begin{array}{l}17.4 \\
(2.8) \\
\end{array}$ & & & $29.3(5.2)$ & & \\
\hline \multirow[t]{3}{*}{ ondent type } & Student & $\begin{array}{l}17.5 \\
(2.6) \\
\end{array}$ & 0.41 & 0.66 & $\begin{array}{l}17.4 \\
(2.9)\end{array}$ & 1.43 & 0.24 & $28.4(5.5)$ & 7.36 & $<0.05$ \\
\hline & Teacher & $\begin{array}{l}17.7 \\
(3.2) \\
\end{array}$ & & & $\begin{array}{l}17.7 \\
(3.3) \\
\end{array}$ & & & $29.8(5.9)$ & & \\
\hline & Parent & $\begin{array}{l}17.4 \\
(3.0) \\
\end{array}$ & & & $\begin{array}{l}17.5 \\
(3.2) \\
\end{array}$ & & & $29.7(5.1)$ & & \\
\hline \multirow[t]{6}{*}{ y site } & Atsbi Wonberta & $\begin{array}{l}17.0 \\
(3.1) \\
\end{array}$ & 11.08 & $<0.01$ & $\begin{array}{l}16.6 \\
(3.5) \\
\end{array}$ & 14.27 & $<0.01$ & $26.6(5.2)$ & 20.2 & $<0.01$ \\
\hline & Dessie & $\begin{array}{l}18.7 \\
(1.4) \\
\end{array}$ & & & $\begin{array}{l}18.8 \\
(1.4)\end{array}$ & & & $32.2(1.3)$ & & \\
\hline & Kemissie & $\begin{array}{l}16.5 \\
(3.1) \\
\end{array}$ & & & $\begin{array}{l}16.2 \\
(3.3) \\
\end{array}$ & & & $26.9(6.3)$ & & \\
\hline & Shoa Robit & $\begin{array}{l}17.8 \\
(2.1) \\
\end{array}$ & & & $\begin{array}{l}17.9 \\
(2.1)\end{array}$ & & & $28.9(4.8)$ & & \\
\hline & Hossana & $\begin{array}{l}17.6 \\
(3.2) \\
\end{array}$ & & & $\begin{array}{l}17.5 \\
(3.3)\end{array}$ & & & $28.9(6.5)$ & & \\
\hline & Butajira & $\begin{array}{l}18.3 \\
(2.5) \\
\end{array}$ & & & $\begin{array}{l}18.1 \\
(2.8)\end{array}$ & & & $31.1(4.8)$ & & \\
\hline
\end{tabular}




\begin{tabular}{l|l|l|l|l|l|l|l|l|l|l|} 
& Assela & $\begin{array}{l}17.7 \\
(2.5)\end{array}$ & & & $\begin{array}{c}18.1 \\
(2.5)\end{array}$ & & & $29.1(5.1)$ & & \\
\hline & Jimma & 16.8 & & & 16.6 & & & $27.4(6.2)$ & & \\
& & $(3.3)$ & & & $(3.7)$ & & & & & \\
\hline
\end{tabular}

$S D=$ Standard deviation; $F=$ Test value for one-way analysis of variance; $t=$ Test value for independent sample $t$-test

\section{Discussion}

In this study, we identified a large number of specific interventions that may help to deal with unsafe youth migration from the perspective of several stakeholders (local government office heads, religious and community leaders, teachers, parents and students). These large numbers of specific interventions were grouped into five domains: awareness and attitudinal/behavioral changes, job opportunities and vocational and life skills training, governmental and parental roles, improving the education system and law enforcement and management of migration. The need to work in cooperation among several stakeholders, including local government offices, schools, the community and non-governmental organizations, was cross-cutting. Randomly selected survey respondents (teachers, parents and students) were asked to indicate their level of agreement about the contextual relevance and effectiveness of these interventions in terms of reducing unsafe youth migration in Ethiopia in particular and improving migration outcomes in general.

We found that a great majority (more than $80 \%$ ) of the respondents endorsed (agreed or strongly agreed) about the effectiveness and contextual relevance of these interventions. One of the interventions (i.e. promoting legal migration), was comparatively less endorsed. Around $27 \%$ of the respondents did not endorse this intervention (disagree or strongly disagree). Overall, the degree of endorsement of the interventions was high and statistically significant difference was not found across most of the background characteristics. Nevertheless, older respondents were higher in the mean values of levels of endorsement of the two domains: "enhancing access to resources and jobs" and "law enforcement and migration management." For the domains "enhancing access to resources and jobs" and "law enforcement and migration management," respondents with higher level of education were more likely to endorse the interventions than those with lower level of education. The level of endorsement of the intervention strategies by students in the domain "law enforcement and migration management" was significantly lower than the level of endorsement by teachers and parents. With regard to study sites, the level of endorsement of intervention strategies in all the three domains was higher in Dessie and Butajira than the other study sites.

There is generally lack of research on effective intervention strategies to reduce unsafe migration and undesirable migration outcomes to compare our findings with. Studies, from different parts of the world, showed that there are several risk factors for unsafe youth migration as well as for undesirable migration outcomes. These include irregular migration [29], low skill labor and knowledge gaps [25], law enforcement and policy gaps [24], family and social pressure [30], border control gaps, political uncertainty in the sending country, unemployment/joblessness and poverty [31], discrimination and 
government corruption [9]. Safer migration interventions are suggested to deal with these risk factors. The specific intervention strategies we identified are more or less related to the above risk factors and hence may potentially be effective to reduce unsafe youth migration and broadly to improve migration outcomes, although this has to be empirically tested through intervention studies.

The intervention strategies identified in this study (e.g. awareness creation activities, creating job opportunities and law enforcement) are also more or less similar with the few interventions that have been previously tested with empirical studies. A non-peer reviewed systematic review report [24] identified interventions that have been tested and found to be effective in South East Asia and South America to reduce unsafe migration. These interventions include the following: awareness campaigns, informational education material distribution, capacity building with local partner organizations and government agencies, employment placement, skill-building, migrant resource centres, hotlines, home visits to migrant families, legal assistance, network building for partners and beneficiaries, outreach activities for beneficiary identification, peer educator training, pre-departure orientation seminars, and psychosocial support. However, some of these interventions (such as hot lines) may not be contextually relevant in the Ethiopian situation. Hence the need for qualitatively identifying contextually appropriate interventions that would be feasible, acceptable and effective to deal with unsafe migration in Ethiopia is justified. Although most of the interventions identified in this study are similar to those reported in the literature, we also come across with a few interventions that are unique to the socio-cultural situation in Ethiopia which are not reported in the literature previously. These include interventions related to making sure that parents fulfill their roles in terms of advising, educating and supporting their children and working on the education system.

More than $80 \%$ of the survey respondents indicated that the intervention strategies we identified with the qualitative study are contextually relevant and potentially effective to deal with unsafe youth migration. We also found that older respondents and respondents with more education endorsed these interventions more than respondents with younger age and those who have lower education. Overall, these findings suggest that the intervention strategies we identified would likely to be feasible, acceptable and effective to reduce unsafe youth migration. Hence, there is need to conduct further research to empirically test the effectiveness of these interventions.

One of the major strengths of this is study is that we used a mixed methods study to qualitatively identify the potential intervention strategies and then test their contextual relevance and potential effectiveness with a survey study using a large sample. We developed the survey instrument following a qualitative study and extensive review of the literature. Although we did not comprehensively determine the psychometric properties of the instrument, its face and content validity were evaluated through a series of expert consensus meeting. In addition, the instrument is found to have fairly good internal consistency reliability. The study is conducted in eight migration hotspot areas in Ethiopia which is likely to represent the context of the country. This study has several limitations, which need to be noted. First, the crosssectional design of the study makes it difficult to determine the direction of relationship between background characteristics and endorsement of intervention strategies. Second, the endorsement of 
intervention strategies by survey respondents is just their opinion, which cannot be taken for granted. Third, although we carefully developed the survey instruments, being informed by a qualitative study and extensive review of the literature, we did not properly validate it. Finally, although our sample (both in the qualitative study and in the survey study) was heterogeneous, we were not able to include migrant returnees.

\section{Conclusions}

In this mixed methods study, we identified intervention strategies that would help to reduce unsafe youth migration and improve migration outcomes in Ethiopia. We grouped these specific intervention strategies into awareness and attitudinal/behavioral changes, job opportunities and vocational and life skills training, governmental and parental roles, improving the education system and law enforcement and management of migration. Most of these intervention strategies are endorsed by more than $80 \%$ of survey respondents in terms of their contextual relevance and potential effectiveness. There is need to prioritize and systematize these intervention strategies and evaluate their feasibility and acceptability using qualitative studies. Experimental studies to test for the effectiveness of the prioritized and systematized intervention strategies are also warranted.

\section{Abbreviations}

FGD: Focus group discussion ILO: International Labor Organization MOE: Ministry of Education PTSA: Parent-Teacher-Student Association SPSS: Statistical Packages for the Social Sciences TVET: Technical and vocational education and training

\section{Declarations}

\section{Acknowledgments}

We are grateful to all the participants for giving their time and the data. We would like to thank the officials in all the study sites for the support they provided to us. We would also like to acknowledge Addis Ababa University for funding.

\section{Funding}

This study was funded by the Office of the Vice President for Research and Technology Transfer, Addis Ababa University; however the views expressed do not necessarily reflect the funder's official policies.

\section{Availability of data and materials}

This study is part of a larger thematic research project. Data used for this analysis will become available through the project. 
$\mathrm{KH}, \mathrm{AM}, \mathrm{FA}, \mathrm{SZ}$ and AT conceived and designed the study. KH, AM, FA, MG, AT, YA and SZ did the data collection. $\mathrm{KH}$ did the data analysis with support from AM. KH drafted the manuscript. All authors agree with the results and conclusions, contributed to the writing of the manuscript and approved the final manuscript to be submitted for publication.

Competing interests

The authors declare that they have no competing interests.

Consent for publication

$N / A$

Ethics approval and consent to participate

The study was approved by the Office of the Vice President for Research and Technology Transfer, Addis Ababa University. Oral informed consent was obtained from all the participants after the nature of the study and the information sought had been fully explained.

\section{References}

1. Bariagaber A: International migration and development in Eastern and Southern Africa. OSSREA; 2014.

2. Bhugra D: Migration and mental health. Acta Psychiatr Scand 2004, 109:243-258.

3. Uchehara K: Sub-Saharan African countries and migration to Europe: Exploring the motivations, effects and solutions. Informatologia 2016, 49:79-85.

4. Office IL: ILO global estimates on migrant workers: Results and methodology. International Training Centre of the ILO Geneva, Switzerland; 2015.

5. Cortina J, Taran P, Elie J, Raphael A: Migration and youth: Challenges and opportunities. Global Migration Group, United Nations, New York, NY 2014.

6. Nwalutu MO: Youth and the 21 st century south-north migration: In search of a more relevant perspective on causes, trend and flow. Sociology Mind 2014, 4:1.

7. Mulugeta M, Makonnen T: Illicit Cross-border Migration in Ethiopia: Causes, Patterns and Policy Responses. Ethiopian Journal of the Social Sciences and Humanities 2017, 13:53-80.

8. Minaye A: Trafficked to the Gulf States: The Experiences of Ethiopian Returnee Women. Journal of Community Practice 2012, 20:112-133.

9. Minaye A, Zeleke WA: Attitude, Risk Perception and Readiness of Ethiopian Potential Migrants and Returnees Towards Unsafe Migration. AFRICAN HUMAN MOBILITY REVIEW:702.

10. Deotti L, Estruch E: Addressing rural youth migration at its root causes: A conceptual framework. Siwzerland 2016. 
11. Roth BJ, Hartnett CS: Creating reasons to stay? Unaccompanied youth migration, community-based programs, and the power of "push" factors in El Salvador. Children and Youth Services Review 2018, 92 48-55.

12. Jamie FOM, Tsega AH: Ethiopian female labor migration to the Gulf states: the case of Kuwait. African and Black Diaspora: An International Journal 2016, 9:214-227.

13. Fernandez B: Household help? Ethiopian women domestic workers' labor migration to the Gulf countries. Asian and Pacific Migration Journal 2011, 20:433-457.

14. Gibson MA, Gurmu E: Rural to urban migration is an unforeseen impact of development intervention in Ethiopia. PLoS One 2012, 7:e48708.

15. Dessiye M, Emirie G: Living and working as a domestic worker in the Middle East: the experience of migrant returnees in Girana town, North Wollo, Ethiopia. African and Black Diaspora: An International Journal 2018, 11:69-86.

16. Hare D: 'Push'versus 'pull'factors in migration outflows and returns: Determinants of migration status and spell duration among China's rural population. The Journal of Development Studies 1999, 35:4572.

17. Rachlis BS, Hogg RS, Wood E, Li K, Kerr T: Factors associated with geographic migration among a cohort of injection drug users. Health Place 2008, 14:536-543.

18. Baker J, Aina TA: The migration experience in Africa. Nordic Africa Institute; 1995.

19. Shi Y, Ji Y, Sun J, Wang Y, Sun X, Li C, Wang D, Chang C: Lack of health risk awareness in low-income Chinese youth migrants: assessment and associated factors. Environmental health and preventive medicine 2012, 17:385.

20. Carballo M, Nerukar A: Migration, refugees, and health risks. Emerg Infect Dis 2001, 7:556-560.

21. Anbesse B, Hanlon C, Alem A, Packer S, Whitley R: Migration and Mental Health: a Study of LowIncome Ethiopian Women Working in Middle Eastern Countries. International Journal of Social Psychiatry 2009, 55:557-568.

22. Busza J, Teferra S, Omer S, Zimmerman C: Learning from returnee Ethiopian migrant domestic workers: a qualitative assessment to reduce the risk of human trafficking. Global Health 2017, 13:71.

23. Habtamu K, Minaye A, Zeleke WA: Prevalence and associated factors of common mental disorders among Ethiopian migrant returnees from the Middle East and South Africa. BMC Psychiatry 2017, 17:144.

24. Zimmerman C, McAlpine A, Kiss L: Safer labour migration and community-based prevention of exploitation: The state of the evidence for programming. London: United Kingdom 2016.

25. Anteneh A: Trafficking in persons overseas for labour purposes: The case of Ethiopian Domestic Workers. ILO; 2011.

26. Chinyakata R, Raselekoane RN: A Study of the Effects of Zimbabwean Youth Migration on. The Social Sciences 2018, 13:357-362. 
27. De Haas H: Migration and development: A theoretical perspective 1. International migration review 2010, 44:227-264.

28. Braun V, Clarke V: Using thematic analysis in psychology. Qualitative research in psychology 2006, 3:77-101.

29. Chantavanich S, Laodumrongchai S, Stringer C: Under the shadow: Forced labour among sea fishers in Thailand. Marine Policy 2016, 68:1-7.

30. Betancourt TS, Shaahinfar A, Kellner SE, Dhavan N, Williams TP: A qualitative case study of child protection issues in the Indian construction industry: investigating the security, health, and interrelated rights of migrant families. BMC public health 2013, 13:858.

31. Jaisat K, Biel E, Pollock J, Press B: Migrant workers in Thailand's garment factories. Chiang Mai, Thailand: Clean Clothes Campaign 2014. 